\title{
The Palaeo-Kambaniru river mouth, Sumba, East Nusa Tenggara, Indonesia: A record of strongly seasonal catastrophic flow in a monsoon- controlled deltaic complex
}

\author{
John-Paul Zonneveld ${ }^{1}$, Yahdi Zaim², Yan Rizal ${ }^{2}$, Aswan $^{2}$, Anne Fortuin ${ }^{3}$, Roy Larick, and \\ Russell L. Ciochon ${ }^{5}$ \\ ${ }^{1}$ Department of Earth and Atmospheric Sciences, University of Alberta, Canada \\ ${ }^{2}$ Department of Geology, Institut Teknologi Bandung, Indonesia \\ ${ }^{3}$ Geomarine centre, Amsterdam, Netherlands \\ ${ }^{4}$ Bluestone Heights, Shore Cultural Centre, Ohio, United States \\ ${ }^{5}$ Department of Anthropology, University of Iowa, United States
}

\begin{abstract}
The Kambaniru River valley near the city of Waingapu preserves a thick succession of coarse-grained fluvial-deltaic sediment deposited during the Late Pleistocene. This succession incises through a thick uplifted coral reef terrace succession and records intervals of highly episodic flow events during the last glacial interval. The occurrence of intraclastic, coarse sand/gravel matrix olistostromes in several areas attests to the occasionally catastrophic nature of flow in the ancestral Kambaniru River. Small to moderate-sized coral-rich reefs and laterally restricted reef terraces occur on deltafront conglomerate successions at multiple horizons through the study interval. These reefs record both intervals of low flow as well as periodic river-mouth avulsion episodes. Comparison of radiometric dates obtained from pelecypod and coral material from both deltaic successions and laterally adjacent coral reef terrace intervals indicates that uplift/subsidence history of the terraces differs from that of the valley and that correlation between the two should be taken with care.
\end{abstract}

Keywords: Kambaniru River, catastrophic river flow, Late Pleistocene, Sumba

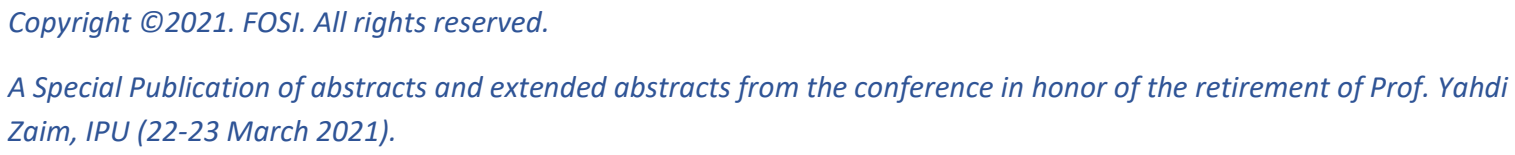




\section{INTRODUCTION}

The Kambaniru River system drains a lot of the eastern portion of the island of Sumba in East Nusa Tenggara, Indonesia and has done so since at least the mid-Pleistocene. Sourced in mixed igneous and sedimentary strata of the Matawai La Pawu highlands in the southern part of the island, the Kambaniru delivers a large volume of siliciclastic sediment to the northeastern, carbonate-dominated coast of the island. The Kambaniru mouth debouches into an embayment on the margin of the Savu Sea where it forms a seasonally alternating riverdominated and wave-influenced deltaic complex. Fringing coral reefs with narrow intertidal to shallow subtidal backreef zones occur both to the east and west, closely adjacent to the river mouth. Coarse sediment is delivered to the river mouth/delta front region only during sporadic high-intensity monsoonal-driven flow intervals.

The Kambaniru River system incises through a thick ( 474 meter) succession of carbonate reef terraces, which are well-developed and readily differentiated on Tanjung Laundi to the west and, to a lesser extent, on Tanjung Watuata to the east of the Kambaniru valley (Figure 1). Seven main terrace intervals have been identified on Tanjung Laundi, from Terrace 0 at present-day sea-level to Terrace interval VI located $\sim 475 \mathrm{~m}$ above sea-level at Palindi Lamajangga (Figure 1). These terraces preserve pristine coral fossils and have been dated using a variety of techniques including Th/U and ESR dating, and
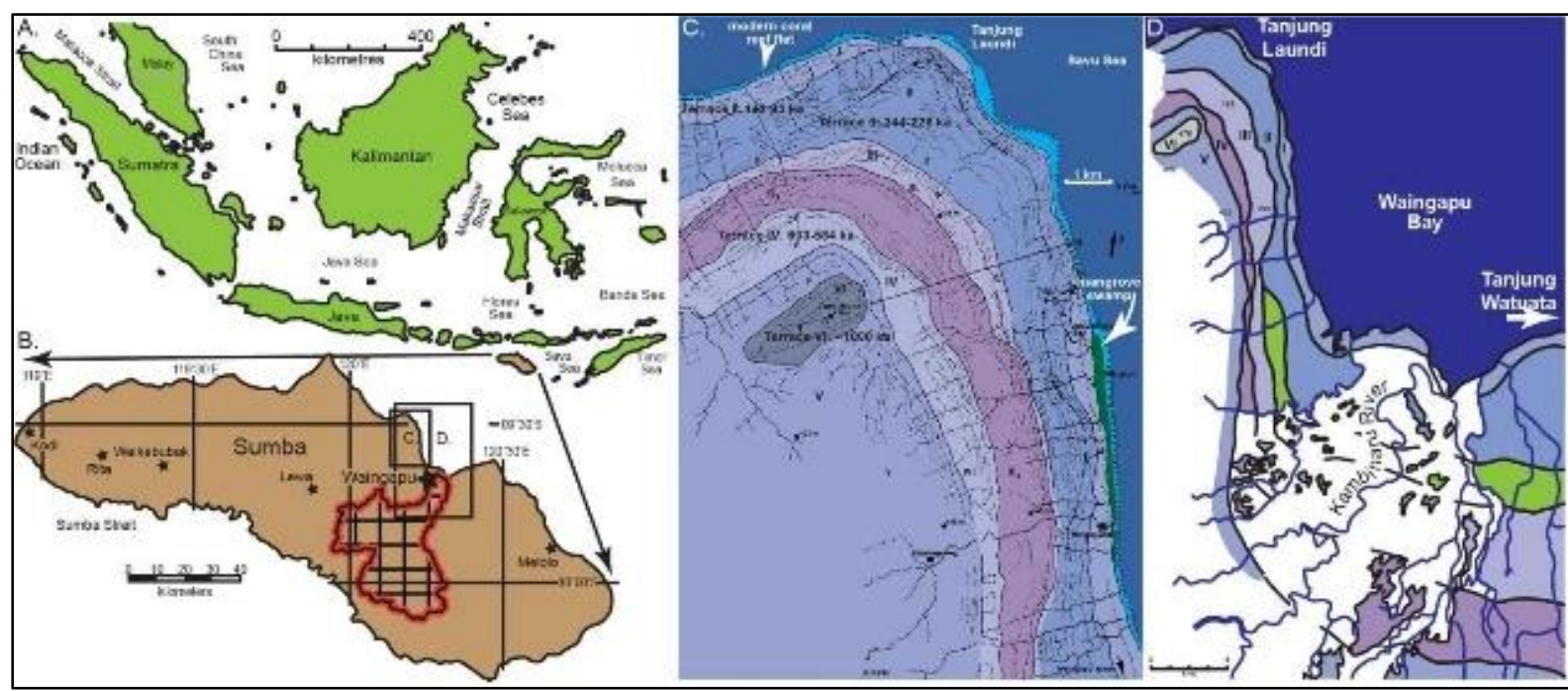

Figure 1. a) Map of Indonesia showing the location of Sumba in the extreme south. b) Map of Sumba showing the location of the Kambaniru watershed (cross-hatched area outlined in red and black) and the location of inset maps $C$ and D. c) The Tanjung Laundi area, which has been the focus of several coral terrace uplift studies referenced herein (after Pirazzoli et al., 1993). d) Schematic geological map showing correlation of coral reef terrace levels across the Kambaniru valley and the region of non-deposition surrounding the Kambaniru River (based on Fortuin, unpublished data). 


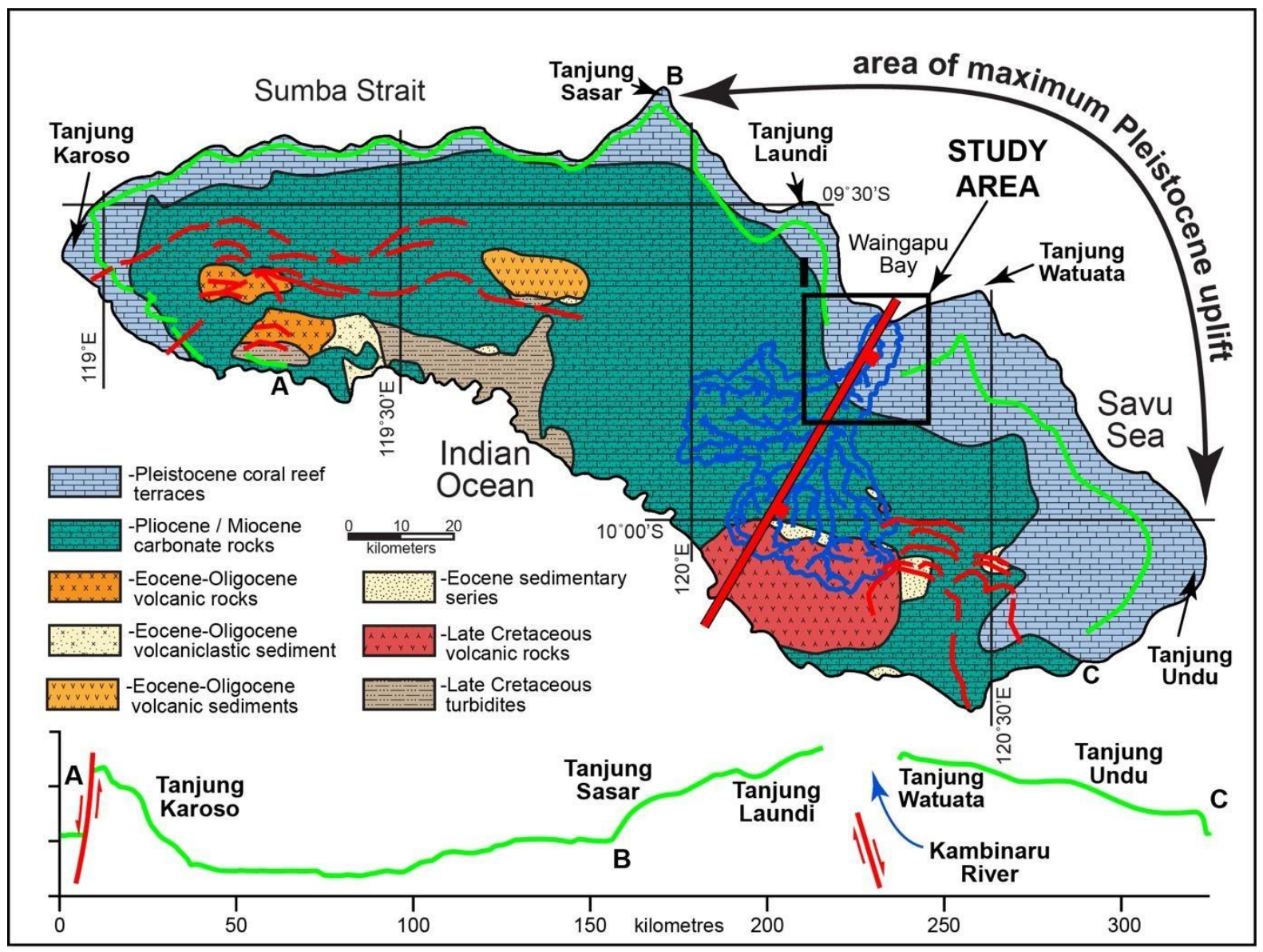

Figure 2. Simplified geological map of Sumba showing the location of the Kambaniru River watershed (blue dendritic lines) and the location of the Marine Isotope Stage (MIS) eleven coral reef terrace (shown in neon green). This terrace provides a datum with which to assess relative uplift along the northern coast of Sumba. At base is a cross section showing the elevation of the MIS 11 coral reef terrace in northern Sumba. Note that there is an area of non-deposition or erosion of the MIS 11 coral reef terrace in the vicinity of the Kambaniru River valley. Basic geological map from Abdullah et al., 2000.

Structural data (shown in red) from Fortuin et al., 1997; Rigg and Hall, 2011. Coral terrace location and elevation profile from Nexer et al., 2015 using data from Pirazzoli et al., $1991 ; 1993$.

correlation with global marine isotope stages (Pirazzoli et al., 1991; 1993; Bard et al., 1996; Nexer et al., 2015). Lateral continuity of terrace intervals has allowed for correlation and extrapolation of uplift rates along the entire northern coast of Sumba (Figure 2; Nexer et al., 2015). Of note, the regional terraces are not identified in the Kambaniru valley due to local non- deposition or erosional removal of coral terraces (Figures 1 and 2).

In the Waingapu area and the hill country surrounding the Kambaniru lowlands outcrop successions are dominated by siliciclastic/ volcaniclastic sediment consisting of medium- to coarse-grained sandstone, pebble and boulder conglomerate and 
sand/gravel matrix olistostrome units (Figure 3). These siliciclastic units incise through laterally adjacent coral reef terrace units but also interstratified with variably extensive coral-rich bioclastic limestone horizons. Siliciclastic units record deposition of the ancestral Kambaniru River system whereas the coral-prone limestone intervals record reef development during intervals of either low sediment delivery or delta-front avulsion. This study focusses on the Kambaniru mixed siliciclasticcarbonate succession and seeks to establish the relationship between Kambaniru-valley sediments and laterally adjacent coral reef terrace successions and elucidate the relationship between episodic sediment delivery, fluvially-derived turbidity, and development of low to moderate diversity coral reefs in the ancestral Kambaniru River delta.

\section{METHODOLOGY}

This study involved description of outcrop successions that occur in quarries, roadcuts and cliff walls in the vicinity of Waingapu and the surrounding hill country. A total of fifty-one outcrop localities were described, with between one and nine sections measured at each outcrop section. Outcrop descriptions focused on lithological content, physical and biogenic sedimentary structures, and fossil content. Each outcrop section was thoroughly photographed with a Canon EOS 5D Mark III full-frame 22.3-megapixel DSLR. Outcrop panoramas were created using Adobe Photoshop -automate- photo-merge option. Lithological samples were obtained from all outcrop sections for thin-section, geochemical and grainsize analyses. Selected samples of shells and corals were submitted for ${ }^{14} \mathrm{C}$ and U-Th dating.

\section{GEOLOGICAL SETTING}

The modern Kambaniru River is a short (118 km long) river with a high gradient and steep-sided profile. Its catchment is the largest on the island of Sumba $\left(1227 \mathrm{~km}^{2}\right)$. The Kambaniru drainage basin extends from a high of 1225 metres at its source on Mount Wanggameti to sea level at its mouth in Kambaniru Bay on the Sawu Sea. Despite its short length, Kambaniru rainfall is highly variable along its length. Rainfall in the interior headwaters area (hill country around Laiwangi Wanggameti National Park) is seasonal, with $\sim 2000-2400 \mathrm{~mm}$ falling primarily during the regional monsoon between November and April (Hobjen et al., 2014). In contrast, the lowlands near the Kambaniru delta receive only 800-860 $\mathrm{mm}$ (primarily between December and March). Thus, flow in the modern Kambaniru is highly episodic and most coarse sediment transport (coarse sand to boulders) occurs during monsoonal-driven wet intervals. Evidence suggests that the ancestral Kambaniru River was also highly episodic.

The island of Sumba occurs at the junction between the Eurasian and Indian-Australian plates (Hall, 2002). It occurs in a tectonically complex and active setting between the Java Trench oceanic subduction zone and the Timor 


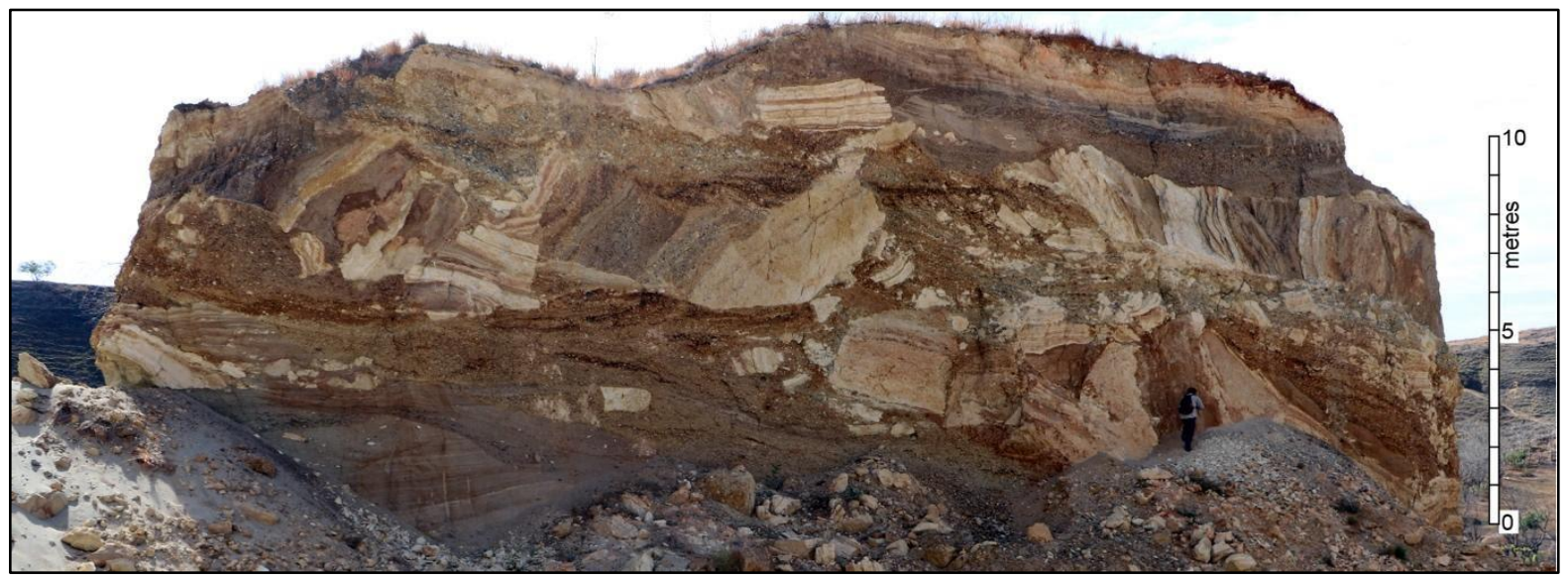

Figure 3. Think olistostrome unit, Okalara Quarry, east of Waingapu. This olistostrome, measured at 7.5 to 9 meters in thickness, and incorporates large siltstone to very fine sandstone olistoliths in random orientation floating in a coarse-grained sandstone to pebble matrix.

Trench / Australian arc collision zone (Hall, 2002; Rigg and Hall, 2011; Nexer et al., 2015). It first emerged in the Early Pliocene (Fortuin et al., 1994; 1997; Rigg and Hall, 2011) and has experienced significant uplift through the Pliocene, Pleistocene, and Holocene (Fortuin et al., 1997; 1999; Pirazzoli et al., 1993; Bard et al., 1995; Nexer et al., 2015). Northern Sumba has experienced significant uplift since the Pliocene with particularly pronounced uplift in the Tanjung Laundi and Tanjung Watuata areas (Figure 1; Pirazzoli et al., 1991; 1993; Nexer et al., 2015).

Previous studies have shown that these terraces were uplifted over the past $\sim 1,000,000$ years and provide an approximately continuous record of reef development in northeastern Sumba during the late Pleistocene and Holocene (Pirazzoli et al., 1991; 1993; Bard et al., 1996; Nexer et al., 2015). Uplift rates are not equivalent across the island of Sumba, with the most pronounced uplift occurring on the western tip of the island near Tanjung Karoso and in northeastern Sumba in the vicinity of Tanjung Laundi and Tanjung Watuata (Figure 2). These latter two capes occur on the immediate east and west of Waingapu Bay. The regional MIS 11 coral reef terrace cannot be identified in the vicinity of the Kambaniru valley due either to non-deposition or erosional removal of the reef terrace in this area. It is also worth noting that the main trend of the northern portion of the lower Kambaniru valley and the axis of Waingapu Bay appear to follow a fault complex that was active through the Pliocene (Fortuin et al., 1997; Rigg and Hall, 2011).

\section{DISCUSSION AND CONCLUSION}

Sediments deposited in the PalaeoKambaniru delta consist of medium to very coarse-grained volcanogenic sand, gravel, cobbles, and boulders. Even in the upstream portion of the study area, 
the occurrence of features such as bored limestone pebbles, bioclasts (particularly bivalves and some corals), oyster and barnacle encrusted pebbles and trace fossil assemblages that include Ophiomorpha (excavated by callianassid shrimp), Schaubcylindrichnus (dwelling traces of suspension- feeding polychaetes) and Psilonichnus (the dwelling traces of crabs) attest to marine incursions that penetrated deep up the Kambaniru valley.

Evidence indicates that the Pleistocene Kambaniru River system was subjected to intervals of stronger and weaker seasonal flow. At several outcrop successions olistostrome units, consisting of multi-decimetre to metre-scale angular clasts in a coarse sand to conglomerate matrix, occur interstratified with cross-stratified conglomerate beds (Figure 3). Olistostrome clasts are typically composed of heterolithic, interbedded, commonly bioturbated sandstone and siltstone. The occurrence of olistostromes in a fluvial-deltaic succession is indicative of catastrophic flood events. ${ }^{14} \mathrm{C}$ dating of shell material that brackets these beds show that these catastrophic event beds are particularly abundant between 36,000 and 33,000 years ago.

Clastic sediment units commonly occur interstratified with sandy/ gravelly bioclastic grainstone/ rudstone beds characterized by corals, bivalves, and gastropods (Figure 4). Although some of these bioclastic rudstone beds are quite small (decimetres thick and 1 to 4 meters wide), in several areas (such as the Mauliru-Pamitimahu Ridge and the Jehari-Kambaniru Peninsula; south and north of the Kambaniru River mouth respectively) thick (4 to $9 \mathrm{~m}$ ), kilometer-scale, tabular to mounded,

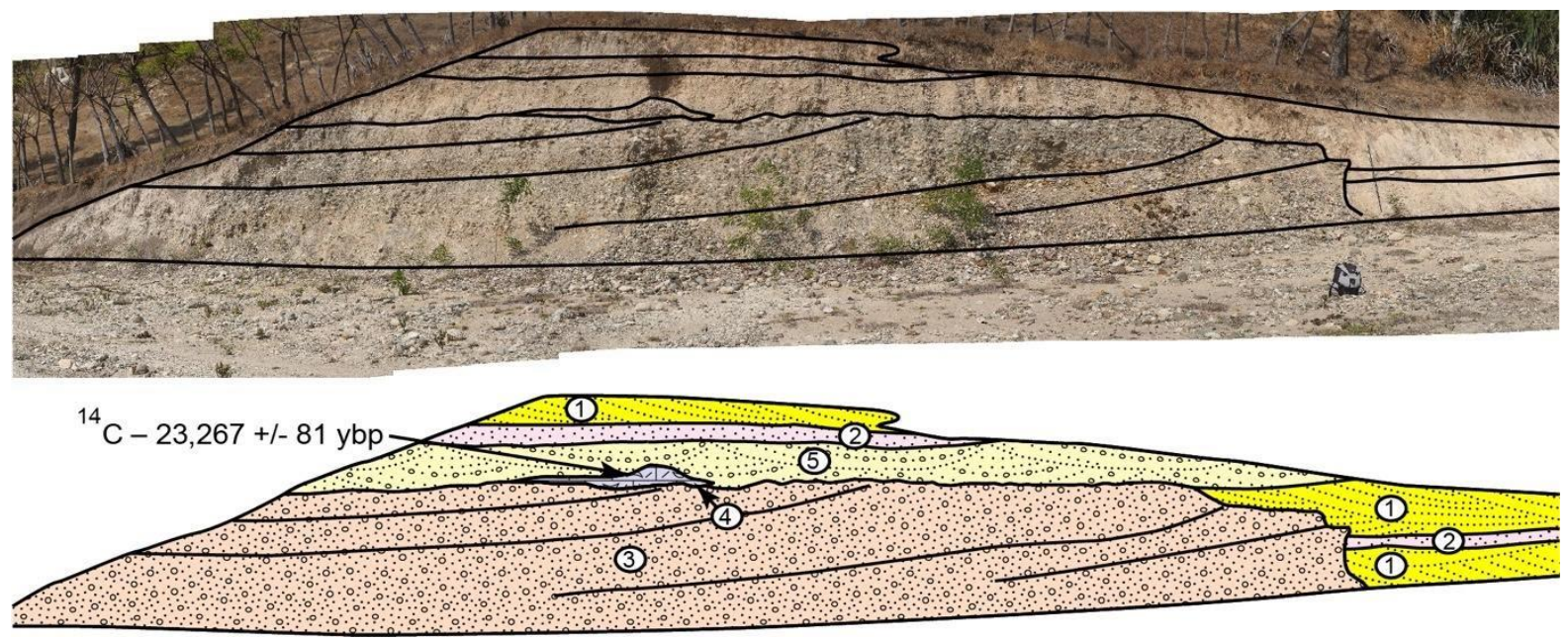

Figure 4. Small patch reef on a distributary-mouth channel fill, West Hambala, Waingapu. Lithofacies 1 is fine-grained, locally bioturbated sandstone; lithofacies two is Lithofacies bioclastic sandstone; lithofacies \#3 is coarse sand matrix, polymodal, polymictic cobble conglomerate; lithofacies \#4 is sandy, pebbly, coralliferous bioclastic limestone; lithofacies \# 5 is a gravel-rich fine-grained sandstone. 
coralliferous rudstone / framestone units characterized by moderate to high diversity coral and pelecypod communities occur on the upper surface of carbonate-rich conglomerate beds.

${ }^{14} \mathrm{C}$ dating of shell material in ancestral Kambaniru deposits throughout the greater Kambaniru valley system reveals a complex scenario of local uplift and subsidence that differs substantively from regional, consistent, coral terrace uplift lateral to (west and east of the study area. Further work is needed, but our working hypothesis is that the Kambaniru-parallel Pliocene fault complex identified by previous researchers (Fortuin et al., 1997; Riggs and Hall, 2011) remained active throughout the Pleistocene and Holocene evolution of the Kambaniru fluvial-deltaic system.

\section{ACKNOWLEDGEMENTS}

Funding for this study was provided through an NSERC Discovery grant to John-Paul Zonneveld and to a National Geographic grant to Gregg F. Gunnell and Russell Ciochon. We are grateful to the contributions and assistance in the field of Gregg F. Gunnell. You are missed old friend!

\section{REFERENCES}

Abdullah, C.I., Rampnoux, J-P., Bellon, H., Maury, R.C. and SoeriaAtmadja, R., 2000. The evolution of Sumba Island (Indonesia) revisited in the light of new data on the geochronology and geochemistry of the magmatic rocks. Jour. Of Asian E. Sci, v. 18 , p. $533-546$.

Bard, E., Jouannic, C., Hamelin, B., Pirazzoli, P.A., Arnold, M., Faure, G., Sumosusastro, P. and Syaefudin, 1996. Pleistocene sea levels and tectonic uplift based on dating of corals from Sumba Island, Indonesia. Geophys. Res. Let., v. 23, p. 14731476.

Fortuin, A.R., Van der Werff, W. and Wensink, H., 1997. Neogene basin history and paleomagnetism of a rifted and inverted forearc region, on- and offshore Sumba, Eastern Indonesia. Jour. Asian E. Sci, v. 15, p. 61-88.

Hobgen, S.E., Myers, B.A., Fisher, R.P. and Wasson, R.J., 2014. Creating a sediment budget in a data poor context: an example from eastern Indonesia. Geograf. Ann.: Ser. A., Phys. Geog., v. 96, p. 513-530.

Nexer, M., Authemayou, C., Schildgen, T., Hantoro, W., Molliex, S., Delcaillau, B., Pedoja, K., Husson, L. and Regard, V., 2015. Evaluation of morphometric proxies for uplift on sequences of coral reef terraces: a case study from Sumba Island. Geomorph. v. 241, p. 145-159.

Pirazzoli, P.A., Radtke, U., Hantoro, W.S. Jouannic, C., Hoang, C.T., Causse, C. and Best, M.B., 1991. 
Quaternary raised coral-reef terraces on Sumba Island, Indonesia. Science, v. 252 , p. $1834-1836$.

Pirazzoli, P.A., Radtke, U., Hantoro, W.S. Jouannic, C., Hoang, C.T., Causse, C. and Best, M.B., 1993. A one million-year-long sequence of marine terraces on Sumba Island, Indonesia. Mar. Geol. v. 109, p. 221-236.
Riggs, J.W.D. and Hall, R., 2011. Structural and stratigraphic evolution of the Savu Basin, Indonesia, In Hall, R., Cottam, M.A., and Wilson, M.E.J. (Editors), The southeast Asian gateway: history and tectonics of the Australia-Asia collision. Geological Society Special Publications, v. 355, p. 225-240. 